\title{
Localized structure in the cusp and high-latitude ionosphere: a modelling study
}

\author{
H. F. Balmforth ${ }^{1}$, R. J. Moffett ${ }^{1}$ and A. S. Rodger ${ }^{2}$ \\ ${ }^{1}$ Upper Atmosphere Modelling Group, School of Mathematics and Statistics, University of Sheffield, Sheffield S3 7RH, UK \\ ${ }^{2}$ British Antarctic Survey, Madingley Road, Cambridge CB3 0ET, UK
}

Received: 16 December 1997 / Revised: 19 August 1998 / Accepted: 11 September 1998

\begin{abstract}
The ionospheric signature of a flux transfer event (FTE) seen in EISCAT radar data has been used as the basis for a modelling study using a new numerical model of the high-latitude ionosphere developed at the University of Sheffield, UK. The evolution of structure in the high-latitude ionosphere is investigated and examined with respect to the current views of polar patch formation and development. A localized velocity enhancement, of the type associated with FTEs, is added to the plasma as it passes through the cusp. This is found to produce a region of greatly enhanced ion temperature. The new model can provide greater detail during this event as it includes anisotropic temperature calculations for the $\mathrm{O}^{+}$ions. This illustrates the uneven partitioning of the energy during an event of this type. $\mathrm{O}^{+}$ion temperatures are found to become increasingly anisotropic, with the perpendicular temperature being substantially larger than the parallel component during the velocity enhancement. The enhanced temperatures lead to an increase in the recombination rate, which results in an alteration of the ion concentrations. A region of decreased $\mathrm{O}^{+}$and increased molecular ion concentration develops in the cusp. The electron temperature is less enhanced than the ions. As the new model has an upper boundary of $10000 \mathrm{~km}$ the topside can also be studied in great detail. Large upward fluxes are seen to transport plasma to higher altitudes, contributing to the alteration of the ion densities. Plasma is stored in the topside ionosphere and released several hours after the FTE has finished as the flux tube convects across the polar cap. This mechanism illustrates how concentration patches can be created on the dayside and be maintained into the nightside polar cap.
\end{abstract}

Key words. Ionosphere (ionosphere-magnetosphere interactions; polar ionosphere). Magnetospheric physics (magnetopause, cusp and boundary layers).

Correspondence to: R. J. Moffett

Fax: + 44114222 3739, e-mail: r.moffett@sheffield.ac.uk

\section{Introduction}

Polar patches, or localized increases in the high-latitude plasma concentration, have been observed for a number of years. They are seen to drift with the background magnetospheric convection velocity and have a nonlocal source of plasma. Weber et al. (1984) were amongst the first to provide evidence for the existence of patches using all-sky images of the $6300 \AA$ airglow. Since then many observations have been made using a variety of instrumentation, including optical, HF and incoherent radar, digital ionosondes and satellites (Buchau et al., 1985; Weber et al., 1986; Buchau and Reinisch, 1991; Rosenberg et al., 1993; Rodger et al., 1994a).

The processes involved in polar patch formation, structure and evolution are still controversial and several means of patch formation have been suggested. In situ production by soft electron precipitation was suggested by Kelley et al. (1982), although most recent mechanisms now support plasma transport rather than in situ formation. Weber et al. (1984) suggest that patchy precipitation in the auroral region with subsequent convection over the polar cap may produce patches. Anderson et al. (1988), Lockwood and Carlson (1992) and Idenden et al. (1997) favour the rapid expansion of the polar cap boundary to lower latitudes bringing higher concentration plasma into the polar cap as a mechanism. Patches may also be associated with the ionospheric signature of a flux transfer event (hereafter referred to as FTEs) which are associated with reconnection on the dayside. FTE structures in the ionosphere have been observed by Pinnock et al. (1993) using HF radar. Rodger et al. (1994b) proposed that FTE features cause one of the mechanisms by which the polar ionosphere is broken up into regions of depleted and enhanced plasma concentration. It is this mechanism that we attempt to model here.

A new model of the high-latitude ionosphere is used in conjunction with recent observations of the cusp and 
polar cap regions made with the EISCAT radar. The EISCAT data set studied show a short-lived localized region of enhanced velocity. These features are thought to be the ionospheric signatures of FTEs (Pinnock et al., 1993). The formation and evolution of this type of structure is modelled using an enhanced velocity in the cusp region to simulate a FTE feature.

The new high-latitude model has been developed by the Upper Atmosphere Modelling Group at the University of Sheffield. It was developed as a tool to investigate the processes occurring in the cusp region of the polar ionosphere and the consequences these have for the structure of the high-latitude ionosphere as a whole. Major new features of the model, in comparison with other models (e.g. Valladares et al., 1996; Idenden et al., 1997), are the ability to study the topside ionosphere by raising the upper boundary to $10000 \mathrm{~km}$ and the inclusion of anisotropic temperatures for $\mathrm{O}^{+}$ions respectively. Both of these features add new detail to the complex processes occurring in the ionosphere during an FTE-type event. The Sheffield high-latitude model is described in the next section.

\section{The Sheffield high latitude (SHL) model}

The SHL model is based on the high-latitude model described by Quegan et al. (1982). The model has been considerably updated and improved and now includes full solutions of the continuity and momentum equations for $\mathrm{O}^{+}, \mathrm{H}^{+}, \mathrm{He}^{+}, \mathrm{NO}^{+}, \mathrm{O}_{2}^{+}$and $\mathrm{N}_{2}^{+}$ions and electrons. The energy balance equation is solved for $\mathrm{O}^{+}, \mathrm{H}^{+}, \mathrm{He}^{+}$and electrons, with anisotropic temperatures parallel $\left(T_{\|}\right)$and perpendicular $\left(T_{\perp}\right)$ to the geomagnetic field being calculated for $\mathrm{O}^{+}$. This provides greater detail during specific events and allows more accurate comparisons with observational data. Calculations are performed for a single tube of magnetic flux drifting under the influence of the magnetospheric convection electric field. Thermal plasma is contained within this flux tube in the F-region and topside ionosphere (Kendall and Pickering, 1967), although currents flow due to ion-neutral and electron-neutral collisions. This approach is taken over the more global type of modelling because it has the advantage of allowing localized effects on an individual tube of plasma to be studied without details being lost over a larger region. A future development of the model will be to include a set of tubes which convect together to provide greater coverage. The flux tube has a top altitude of $10000 \mathrm{~km}$, which allows both topside and Fregion effects to be examined. TIROS (Fuller-Rowell and Evans, 1987) and DMSP satellite data are used as inputs to the model to determine precipitation levels for the auroral and cusp regions. The MSIS86 thermospheric model (Hedin, 1987) provides the neutral atmosphere concentrations. Thermospheric wind values are obtained for compatible runs of the Sheffield/UCL/SEL coupled thermosphere-ionosphere-plasmasphere (CTIP) model (Millward et al., 1996).

\subsection{Boundary conditions}

The diffusion equation is solved for $\mathrm{O}^{+}, \mathrm{H}^{+}$, $\mathrm{He}^{+}, \mathrm{NO}^{+}, \mathrm{O}_{2}^{+}$and $\mathrm{N}_{2}^{+}$ions and electrons. The velocity of the ions at the top of the plasma tube acts as the upper boundary condition. The $\mathrm{H}^{+}$upper velocity is based on extrapolation of satellite data from lower altitudes (Hoffman and Dodson, 1980), while the $\mathrm{O}^{+}$ and molecular ions have zero velocity at the top of the tube (10 $000 \mathrm{~km}$ altitude). The $\mathrm{He}^{+}$upper velocity is either set to zero or put equal to the $\mathrm{H}^{+}$value; zero was taken for this study.

The energy balance equation is solved for $\mathrm{O}^{+}, \mathrm{H}^{+}$ and $\mathrm{He}^{+}$ions and electrons. The molecular ion temperatures are put equal to the averaged $\mathrm{O}^{+}$ion temperature. As the field lines are open in the polar ionosphere the magnetospheric electron heat flux has to be taken into account and provides the upper boundary condition for the electron energy balance equation. Electron temperature is found to be highly sensitive to this upper heat flux condition, which is highly variable and poorly measured. The values used in this present model vary according to position in the polar cap and are based on the modelling work of Schunk et al. (1986) who studied a period of similar solar and geomagnetic conditions. The auroral region is considered to be the hottest, the dayside has an intermediate heat flux value and the polar cap is taken as being the coldest region having no magnetospheric heat flux. Values for each region are shown in Table 1.

\subsection{Anisotropic code}

The SHL model has recently been adapted to take into account the $\mathrm{O}^{+}$temperature anisotropy along the geomagnetic field lines and follows the method of Moffett et al. (1993). The model frictional heating term $\left(F_{i n}\right)$ is partitioned into the parallel and perpendicular components according to ion frictional heating partition coefficients $B_{\|}$and $B_{\perp}$. These depend on the composition of the ion and neutral gases and are based on the values of the ion temperature coefficients $\beta_{\|}$and $\beta_{\perp}$ given in Winkler et al. (1992). $B_{\|} F_{i n}$ and $B_{\perp} F_{\text {in }}$ are included in the parallel and perpendicular ion energy balance equations respectively. Typical values of $\mathrm{B}_{\|}$and $\mathrm{B}_{\perp}$ (Jenkins et al., 1997) are shown in Table 2.

The partitioning of the ion distribution allows the $\mathrm{O}^{+}$ ion distribution to become anisotropic according to equations given in, for example, Ganguli et al. (1987) and Gombosi and Rasmussen (1991). The isotropic temperature, which is output from the model for $\mathrm{H}^{+}, \mathrm{He}^{+}$and electrons, is calculated from the energy

Table 1. Values for the downward magnetospheric electron heat flux

$\begin{array}{ll}\text { Cusp } & 3 \times 10^{14} \mathrm{eVm}^{-2} \mathrm{~s}^{-1} \\ \text { Dayside } & 1 \times 10^{14} \mathrm{eVm}^{-2} \mathrm{~s}^{-1} \\ \text { Nightside } & 0.5 \times 10^{14} \mathrm{eVm}^{-2} \mathrm{~s}^{-1} \\ \text { Polar cap } & 0.0\end{array}$


Table 2. Values of the ion frictional heating partition coefficients for the atmospheric composition shown (following Winkler et al., 1992)

\begin{tabular}{lcc}
\hline Ion composition & $100 \% \mathrm{O}^{+}$ & $100 \% \mathrm{O}^{+}$ \\
Neutral composition & $100 \% \mathrm{O}$ & $100 \% \mathrm{~N}_{2}$ \\
$B_{\|}$ & 0.300 & 0.840 \\
$B_{\perp}$ & 1.335 & 1.065 \\
\hline
\end{tabular}

balance equation described in detail by Bailey and Sellek (1990). For the $\mathrm{O}^{+}$ions this is now replaced by

$$
\begin{aligned}
\frac{3}{2} k N \frac{\mathrm{d} T_{\|}}{\mathrm{d} t} & \kappa_{\|} \frac{\partial^{2} T_{\|}}{\partial s^{2}}+\left\{\frac{1}{A} \frac{\partial}{\partial s}\left(\kappa_{\|} A\right)-\frac{3}{2} k N V_{\|}\right\} \frac{\partial T_{\|}}{\partial s} \\
& -3 k N \frac{\partial V_{\|}}{\partial s} T_{\|}+Q_{\|}+B_{\|} F_{i n} \\
& -3 \kappa_{\perp}\left\{\frac{1}{A} \frac{\partial A}{\partial s} \frac{\partial T_{\perp}}{\partial s}+\left(\frac{1}{A} \frac{\partial A}{\partial s}\right)^{2} \frac{T_{\perp}}{T_{\|}}\left(T_{\|}-T_{\perp}\right)\right\}
\end{aligned}
$$

for the $\mathrm{O}^{+}$parallel temperature (where an error in Eq. 2 of Moffett et al., 1993 has been corrected) and by

$$
\begin{aligned}
\frac{3}{2} k N \frac{\mathrm{d} T_{\perp}}{\mathrm{d} t} & \kappa_{\perp} \frac{\partial^{2} T_{\perp}}{\partial s^{2}}+\left\{\frac{1}{A} \frac{\partial}{\partial s}\left(\kappa_{\perp} A\right)+\frac{\kappa_{\perp}}{A} \frac{\partial A}{\partial s}-\frac{3}{2} k N V_{\|}\right\} \frac{\partial T_{\perp}}{\partial s} \\
& -\frac{3}{2} k N V_{\|} \frac{1}{A} \frac{\partial A}{\partial s} T_{\perp}+Q_{\perp}+B_{\perp} F_{i n} \\
& +2 \kappa_{\perp} \frac{T_{\perp}}{T_{\|}}\left(T_{\|}-T_{\perp}\right)\left(\frac{1}{A} \frac{\partial A}{\partial s}\right)^{2} \\
& +\frac{\partial}{\partial s}\left\{\kappa_{\perp} \frac{T_{\perp}}{T_{\|}}\left(T_{\|}-T_{\perp}\right)\left(\frac{1}{A} \frac{\partial A}{\partial s}\right)\right\}
\end{aligned}
$$

for the perpendicular temperature component, where

$\frac{\mathrm{d} T}{\mathrm{~d} t}=\frac{\partial T}{\partial t}+\left(V_{\perp} \cdot \nabla T\right)$

and $V_{\perp}$ is the $E \times B$ drift velocity, $Q$ is the heating rate, $F_{i n}$ is the frictional heating rate, $A$ is the cross-sectional area of the flux tube and $\kappa_{\|}$and $\kappa_{\perp}$ are the thermal conductivities. Uneven partitioning of the energy occurs as the anisotropic temperatures are not symmetrical: pressure anisotropy and the diverging magnetic field affect $T_{\perp}$, while perpendicular heat flow affects $T_{\|}$. This can have important consequences during heating events. The average three-dimensional temperature is given by

$T_{i}=\frac{1}{3}\left(T_{\|}+2 T_{\perp}\right)$

This is the value used for the molecular ion temperature. Greater detail of the method used to calculate anisotropic temperatures is given in Moffett et al. (1993).

\section{The flux transfer event: experimental data}

The model FTE feature was based on an event observed by the EISCAT radar as it scanned northward in beam splitting mode on 29 March, 1992. The data come from EISCAT special programme SP-UK-CONV; in this experiment the UHF beam points at $20^{\circ}$ elevation along the geomagnetic meridian. This gives measurements of the poleward component of the flow, providing the fieldaligned flows are negligible. During an FTE type of event this may not hold and errors of the order of $100 \mathrm{~ms}^{-1}$ may occur. The VHF radar points at $15^{\circ}$ to the east of the geomagnetic meridian at an elevation of $30^{\circ}$. The separation of the two radar beams lies between 100 and $200 \mathrm{~km}$ at the range of interest. The line-of-sight velocities of the two radars can be combined to produce velocity vectors. This makes the assumptions that the flow between the radars is roughly $L$-shell aligned and constant between the two beams. The time resolution of the measurements is approximately $10 \mathrm{~s}$.

The radar data show a region of greatly enhanced plasma velocity (Fig. 1a) in the latitude range $72^{\circ}$ to $77^{\circ} \mathrm{N}$. Associated with this is a region of reduced electron concentration (Fig. 1b). The altitude of the measurements varies with the radar range from approximately $200 \mathrm{~km}$ to $600 \mathrm{~km}$. Within the enhanced region the measured velocity is observed to increase to a maximum of $2.5 \mathrm{~km} \mathrm{~s}^{-1}$; the ion and electron temperatures are seen to rise to over $2200 \mathrm{~K}$ and $2900 \mathrm{~K}$ respectively. The event lasts for approximately $7 \mathrm{~min}$.

To model a FTE-type feature, an additional velocity is added to the model convection velocity. The velocity enhancement occurs as the flux tube passes through the cusp region of precipitation. This is within the range $74^{\circ}$ to $76^{\circ} \mathrm{N}$ latitude. The model FTE feature has a maximum velocity enhancement of $2.5 \mathrm{~km} \mathrm{~s}^{-1}$ which builds up linearly over $100 \mathrm{~s}$, lasts for $5 \mathrm{~min}$ and then decreases linearly to the unperturbed level over $10 \mathrm{~s}$. This is consistent with other observations of FTEs (e.g. Pinnock et al., 1993). The EISCAT data are used as a basis for this velocity enhancement structure but a direct case study is not attempted. An exact match of model and data details (e.g. UT, latitude and longitude) is therefore not made; instead a general study of this type of feature is made.

Figure 2 illustrates the path the model flux tube follows as it convects under the influence of the magnetospheric electric field. The regions of velocity enhancement (dashed area) and cusp precipitation (boxed area) are also shown. In the following section results are presented for two points on this path. Point $A$ at 9:23 UT is in the cusp and is at the centre of the enhanced velocity region. Point $B$ is at 9:53 UT, after the enhancement has finished, when the plasma tube has passed further into the polar cap. These points relate purely to the modelling work and are not intended to represent a specific region or UT covered by the EISCAT radar data shown in Fig. 1.

\section{Results and discussion}

\subsection{Concentrations and fluxes}

Model runs are performed for 29 March, 1992, $F_{10.7}=165, A_{p}=15$. Modelled $\mathrm{O}^{+}, \mathrm{H}^{+}$and molecular 
Experiment : SP-UK-CONV

Time Interval : 09:30:00 29 March 1992 - 11:00:00 29 March 1992

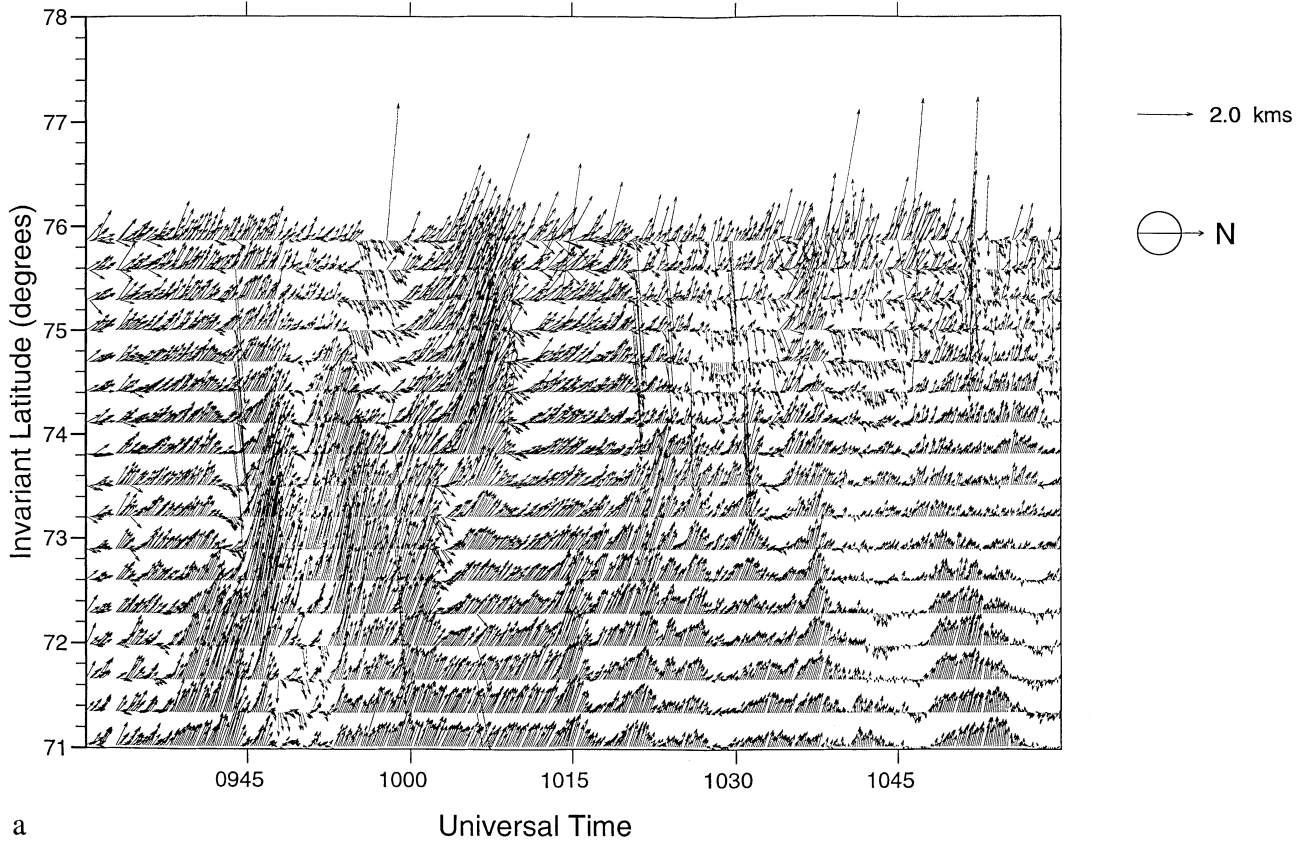

\section{EISCAT Electron Concentration March 291992}

Experiment : SP-UK-CONV UHF Azimuth 344.8 Degrees

Time Interval : 09:30:00 29 March 1992 - 11:00:00 29 March 1992

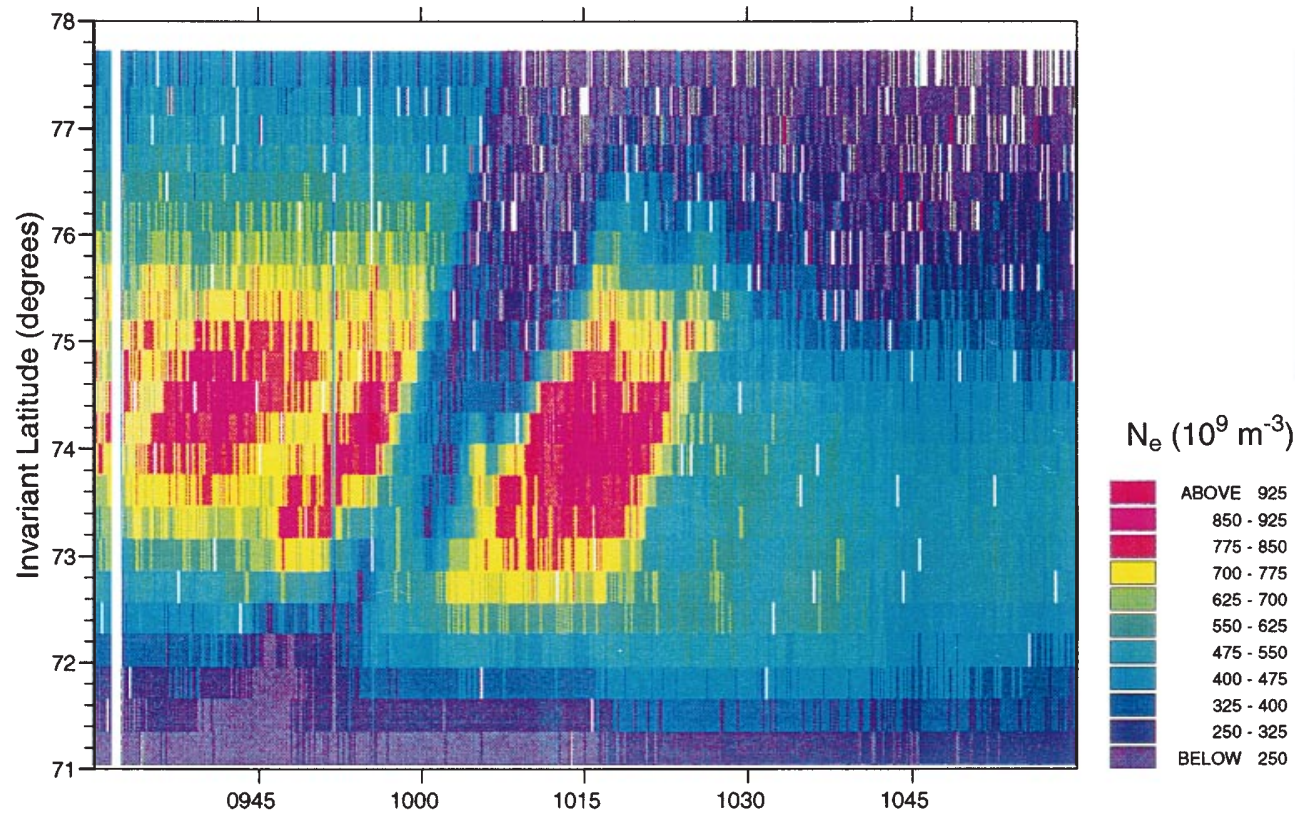

Fig. 1a, b. EISCAT data for 29 March, 1992. a Ion velocity vectors; b electron concentration data

Universal Time

ion concentrations are shown in Figs. 3 and 4 respectively. Values are calculated as the plasma tube follows the path shown in Fig. 2. The plots show concentrations at points $A$ and $B$ (Fig. 2) as the tube passes through the cusp and polar cap regions. The modelled FTE commences at 9:18 UT; results for point $A$, shown by the short dashed lines, are at 9:23 UT in the middle of the FTE. Results for point $B$, shown by the long dashed lines, are for 9:53 UT, 30 min later.

Initially, when the enhanced velocity is applied, a decrease in $N_{m} F 2$, an increase in $h_{m} F 2$ and a depletion in the $\mathrm{O}^{+}$and $\mathrm{H}^{+}$concentrations below approximately $500 \mathrm{~km}$ are seen (Fig. 3). The concentrations of the molecular ions are found to increase during this period due to the increased conversion rate of $\mathrm{O}^{+}$ions into 


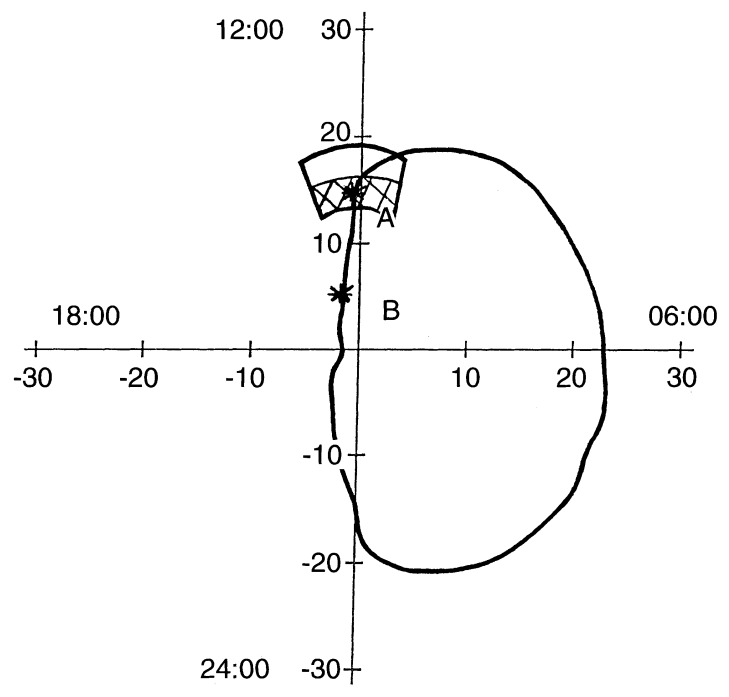

Fig. 2. The path through the cusp and polar cap followed by the model plasma tube. The velocity enhancement (shaded area) occurs within the cusp region of precipitation (boxed area). The plot shows MLT and the position in geomagnetic coordinates, $(\theta, \phi)$. Points $A$ and $B$ illustrate the position of the flux tube in the following result plots

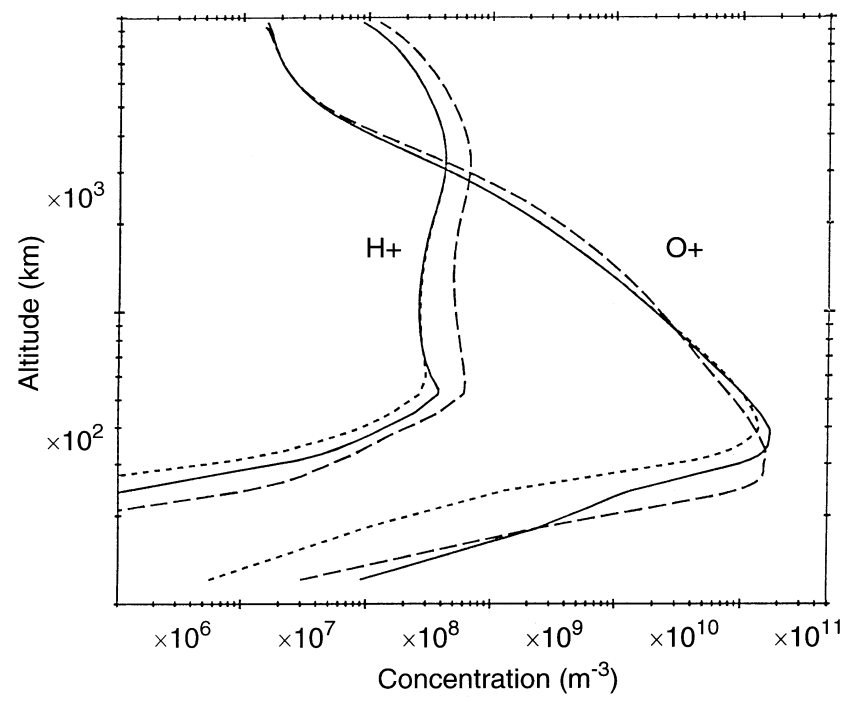

Fig. 3. Model $\mathrm{O}^{+}$and $\mathrm{H}^{+}$ion concentrations during the enhanced velocity event at 9:23 UT (-- -), point $A$ on path, and at 9:53 UT (--), point $B$ on the path. Concentrations with no enhanced velocity are shown for comparison $(-)$

molecular ions (Fig. 4). At point $B, 30$ min after the velocity enhancement, the $\mathrm{H}^{+}$concentration is above the level expected with no enhancement. The $\mathrm{O}^{+}$ concentration profile has altered by this point also, with more plasma being stored at lower $(<300 \mathrm{~km})$ and higher $(>1000 \mathrm{~km})$ altitudes than when there is no enhancement (Fig. 3).

The initial reduction in $\mathrm{O}^{+}$concentration is partly caused by an increased reaction rate of $\mathrm{O}^{+}$with the neutrals $\mathrm{N}_{2}$ and $\mathrm{O}_{2}$, as shown by the increase in molecular content seen in Fig. 4, and partly by an increase in the flux up the plasma tube away from the $\mathrm{F}$

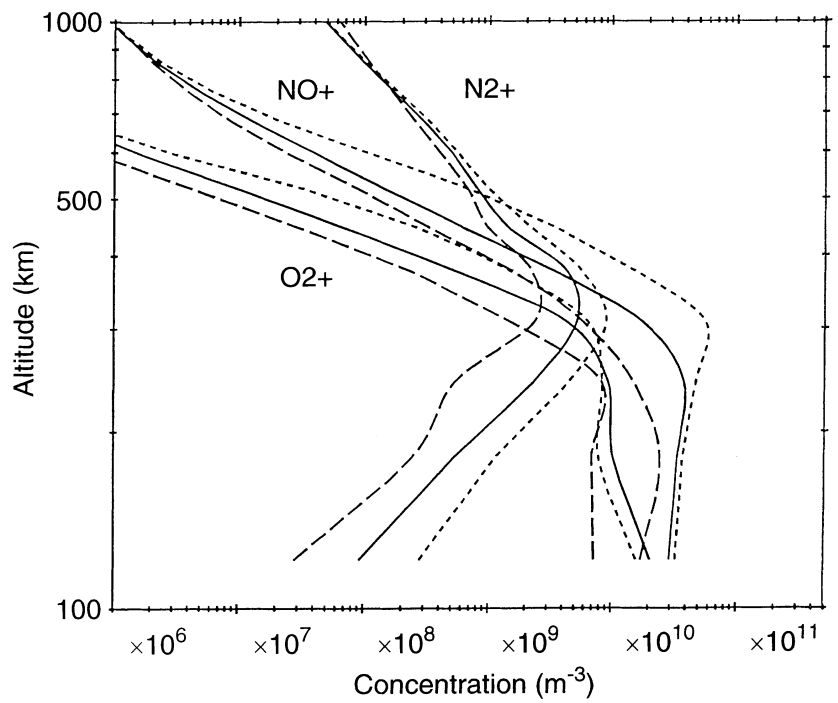

Fig. 4. Model $\mathrm{NO}^{+}, \mathrm{O}_{2}^{+}$and $\mathrm{N}_{2}^{+}$ion concentrations during the enhanced velocity event at 9:23 UT (-- ), point $A$ on path, and at 9:53 UT (- - ), point $B$ on the path. Concentrations with no enhanced velocity are shown for comparison $(-)$

region. Modelled $\mathrm{O}^{+}$flux values are presented in Fig. 5 during the velocity enhancement (dashed lines) and also for no additional velocity for comparison (full lines). At the start of the event the upward flux is enhanced between 300 to $1000 \mathrm{~km}$ altitude. The flows of $\mathrm{O}^{+}$ions away from the plasma pressure bulge are a result of the higher ion temperatures. These fluxes are of comparable significance to the chemical loss. A small increase in $\mathrm{O}^{+}$ concentration is visible at higher altitudes, between approximately 500 to $1000 \mathrm{~km}$, as a result of this increased upward flux (Fig. 3). Further into the event the plasma undergoes a redistribution. After $30 \mathrm{~min}$ a large storage of plasma has occurred in the topside $(>1000 \mathrm{~km})$. This then starts to fall down the tube, shown by the large increase in downward flux, see Fig. 5. As a result the $\mathrm{F}$ peak is lowered and $\mathrm{O}^{+}$concentration below $h_{m} F 2$ is increased. This causes the concentrations of the molecular ions to decrease to below the unperturbed level (Fig. 4). The plasma continues to move back down to F-region heights over approximately $3 \mathrm{~h}$ as the flux tube passes through the polar cap and into the nightside.

The response of the F-region to imposed short-lived velocity features of the type modelled here has been discussed in previous work. Schunk et al. (1975, 1976) first modelled the effects of increasing electric fields on ion and molecular concentrations at high latitudes. They report an increasing dominance of molecular ions in the $\mathrm{E}$ and $\mathrm{F}$ regions as the electric field strength increases. Our results also show a clear switch to increased molecular content in the ionosphere as a result of the enhanced velocity. Simulations of passes through the cusp, including the effects of particle precipitation and intense localized electric fields, have been made by Whitteker (1977), Schunk and Sojka (1989) and Loranc and St-Maurice (1994). These studies report similar fluxes and plasma redistributions and agree well with the 


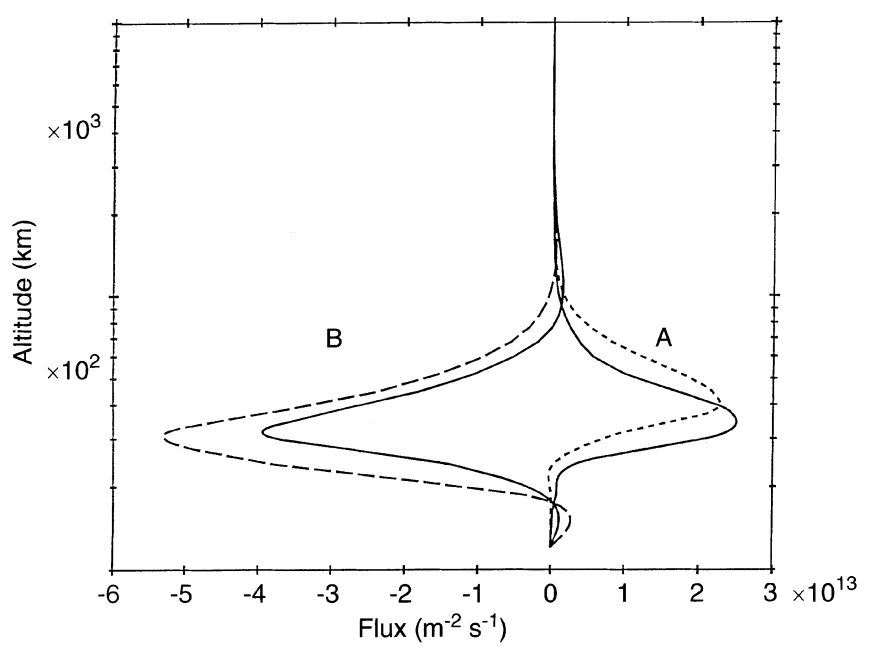

Fig. 5. Model $\mathrm{O}^{+}$flux values during the enhanced velocity event at 9:23 UT (- - ), point $A$ on path, and at 9:53 UT (--), point $B$ on the path. Fluxes at these points with no enhanced velocity are shown for comparison (-), Positive flux is upwards, negative values represent downward fluxes

results presented here. Caton et al. (1996) model the undisturbed ionosphere over EISCAT and report fluxes of the order of $10^{13} \mathrm{~m}^{-2} \mathrm{~s}^{-1}$, which they attribute to the effects of precipitation and the magnetospheric electron heat flux. These fluxes compare well with the values presented in Fig. 5. Valladares et al. (1996) investigate the formation of polar patches in relation to large plasma flows. Using Sondrestrom incoherent scatter radar data, in conjunction with an ionospheric model, they also found enhanced recombination of $\mathrm{O}^{+}$contributes to the creation of low concentration regions.

\subsection{Temperatures}

Figure 6 illustrates modelled temperatures for the $\mathrm{O}^{+}$ ions and electrons. The $\mathrm{O}^{+}$anisotropic temperature is

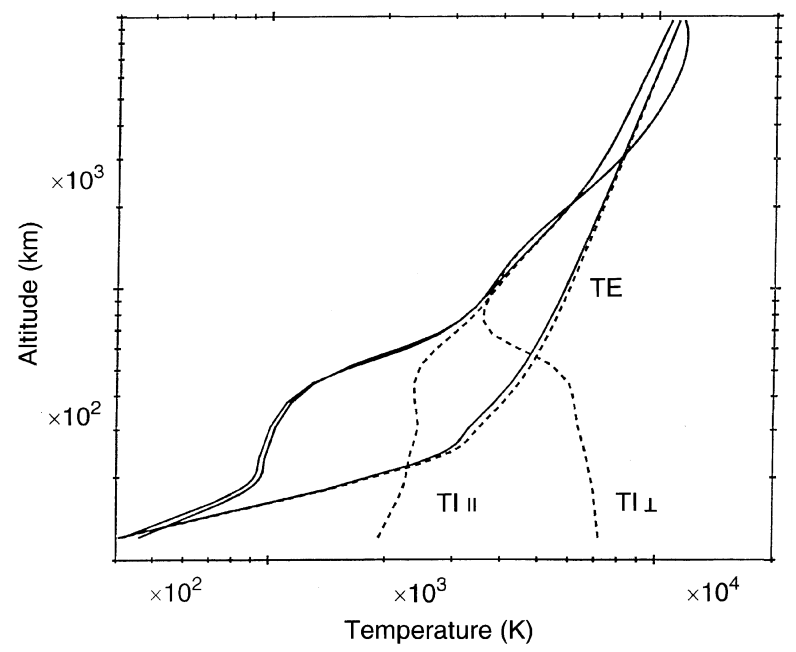

Fig. 6. Model electron and $\mathrm{O}^{+}$anisotropic parallel $\left(T_{\|}\right)$and perpendicular $\left(T_{\perp}\right)$ temperatures for no enhancement $(-)$ and during the enhanced velocity event (-- ), at 9:23 UT, point $A$ on the path split into the parallel and perpendicular components. The solid lines are for no velocity enhancement and the dashed lines are with the enhancement. Values of temperatures are only plotted for point $A$ on the path as the effects in the temperatures are short-lived. The values of parallel and perpendicular temperature in the absence of an FTE are approximately the same as shown in Fig. 6. A very large increase in ion temperature below approximately $2000 \mathrm{~km}$ is observed when the enhanced velocity is applied. The increase in the electron temperature is much smaller. The increase in ion temperature is due to ion-neutral frictional heating which is balanced by ion-neutral heat exchange. The electron temperature is raised somewhat by ion-electron heat transfer, but is still dominated by the heat input from the magnetosphere in the form of the magnetospheric electron heat flux (see Table 1).

When the velocity enhancement is added both the parallel and perpendicular temperatures are greatly increased. The energy is not partitioned evenly, however, with the perpendicular component being up to three times as large as the parallel. The maximum temperature increase for both components occurs below $1000 \mathrm{~km}$. Above this altitude, the heat interchange between the parallel and perpendicular components acts to bring the two temperatures together. The effect of the velocity enhancement is largely observed below approximately $1000 \mathrm{~km}$. At F-region altitudes, the large increase is caused by frictional heating. The temperature increase dissipates to higher altitudes by advection and conduction, with a cut off at approximately $1000 \mathrm{~km}$; this is clearly seen in Fig. 6. When there is no additional velocity the parallel and perpendicular temperatures are very similar. The ion temperature decreases immediately $(<1 \mathrm{~min})$ the FTE finishes, while the electron temperature still increases slightly.

Anisotropic ion temperatures have been modelled by Davies et al. (1995) and Jenkins et al. (1997). Both studies compare EISCAT data with model results and consistently find increasing temperature anisotropy during ion frictional heating events. The F-region ionosphere is found to become increasingly more molecular during these events. Lockwood et al. (1993) present a study of $\mathrm{O}^{+}$anisotropic temperatures measured by EISCAT. They provide tables of the ion temperature partition coefficient, $\beta_{\|}$, which have been derived from theory and experiment. These compare well with the values from this study.

\section{Summary}

An FTE-type feature has been modelled by applying a large velocity enhancement to the plasma as it convects through the cusp precipitation region. This causes a rapid increase in the ion temperature as a result of frictional heating, which leads to an increase in the rate of $\mathrm{O}^{+}$recombination with the molecular ions and an increased upward flux of $\mathrm{O}^{+}$into the topside ionosphere. Both of these processes lead to a decrease in $\mathrm{O}^{+}$ ions in the F-region and an increase in the molecular ion 
concentration in the lower F-region. The electron temperature is less affected and lags behind the ion temperature enhancement. A detailed study of the thermal balance of the ionosphere during an event of this type has been made possible by the inclusion of anisotropic $\mathrm{O}^{+}$ion temperatures in the model calculations. The results show that this makes a significant difference, with the perpendicular temperature being enhanced to a much greater extent than the parallel component. This affects the large fluxes that are produced as a result of this heating. Upward flux is found to increase at higher altitudes and plasma concentration in the topside is enhanced.

As the velocity enhancement continues, the decrease in $\mathrm{O}^{+}$and $\mathrm{H}^{+}$concentration at F-region altitudes becomes larger as does the decrease in $N_{m} F 2$, although the increase in $\mathrm{O}^{+}$concentration at higher altitudes is enhanced. Plasma flux up the tube is reduced while the downward flux is increased. The plasma undergoes a redistribution 30 min after the FTE has finished when large downwards fluxes are observed. During this period $\mathrm{O}^{+}$and $\mathrm{H}^{+}$concentration increase slightly as plasma diffuses back down the tube. This continues over a period of approximately $3 \mathrm{~h}$ as the flux tube convects over the polar cap.

The modelled FTE provides a mechanism for causing localized depletions of plasma accompanied by enhancements in the ion and electron temperatures. This compares well with the observations made by EISCAT during a FTE type feature and is thought to provide one method for the production of polar patches (Rodger et al., 1994b). The new features of this model have been used to illustrate that chemistry and transport are both important in this process. Further work is intended to elucidate the effects of plasma path trajectories through the FTE region and to determine the role of ion and electron cusp precipitation in determining high-latitude ionospheric structure.

Acknowledgements. The work presented was supported by NERC (BAS SWIMS project) under grant number GST/02/1101. The authors are grateful to M. Lockwood, I. W. McCrea and V. Davda for their help. They also gratefully acknowledge the use of data from the EISCAT radar facility. EISCAT is an international facility supported by the national science councils of Finland, France, Germany, Norway, Sweden and the UK.

Topical Editor D. Alcaydé thanks W. Burke and P. E. Sandholt for their help in evaluating this paper.

\section{References}

Anderson, D. N., J. Buchau, and R. A. Heelis, Origin of density enhancements in the winter polar cap ionosphere, Radio Sci., 23, 513, 1988.

Bailey, G. J., and R. Sellek, A mathematical model of the Earth's plasmasphere and its application in the study of $\mathrm{He}^{+}$at $\mathrm{L}=3$, Ann. Geophysicae, 8, 171, 1990.

Buchau, J., and B. W. Reinisch, Electron density structures in the polar F region, Adv. Space Res., 11, 29, 1991.

Buchau, J., E. J. Weber, D. N. Anderson, H. C. Carlson, and J. G. Moore, Ionospheric structures in the polar cap: their origin and relation to $250 \mathrm{MHz}$ scintillation, Radio Sci., 20, 325, 1985.
Caton, R., J. L. Horwitz, P. G. Richards, and C. Liu, Modelling of F region ionospheric upflows observed by EISCAT, Geophys. Res. Lett., 23, 1537, 1996.

Davies, J. A., M. Lester, B. Jenkins, and R. J. Moffett, Dayside ion frictional heating: EISCAT observations and comparisons with model results, J. Atmos. Terr. Phys., 57, 775, 1995.

Fuller-Rowell, T. J., and D. S. Evans, Height-integrated Pedersen and Hall conductivity patterns inferred from the TIROSNOAA satellite data, J. Geophys. Res., 92, 7606, 1987.

Ganguli, S. B., H. G. Mitchell Jr, and P. J. Palmadesso, Behaviour of ionized plasma in the high latitude topside ionosphere, Planet. Space Sci., 35, 703, 1987.

Gombosi, T. I., and C. E. Rasmussen, Transport of gyrationdominated space plasma of thermal origin. 1. Generalized transport equations, J. Geophys. Res., 96, 7759, 1991.

Hedin, A. E., MSIS-86 thermospheric model, J. Geophys. Res., 92, 4649, 1987.

Hoffman, J. H. and W. H. Dodson, Light ion concentrations and fluxes in the polar region during magnetically quiet times, $J$. Geophys. Res., 85, 626, 1980.

Idenden, D. W., R. J. Moffett, and S. Quegan, Ionospheric structure produced during a rapid polar cap expansion, J. Geophys. Res., 102, 14581, 1997.

Jenkins, B., R. J. Moffett, J. A. Davies, and M. Lester, Nightside ion frictional heating: atomic and molecular ion temperature anisotropy and ion composition changes, J. Atmos. Solar-Terr. Phys., 59, 1, 1997.

Kelley, M. C., J. F. Vickrey, C. W. Carlson, and R. Torbert, On the origin and spatial extent of high latitude $\mathrm{F}$ region irregularities, J. Geophys. Res., 87, 4469, 1982.

Kendall, P. C., and W. M. Pickering, Magnetospheric diffusion at F2-region altitudes, Planet. Space. Sci., 15, 825, 1967.

Lockwood, M., and H. C. Carlson, The production of polar cap electron patches by transient magnetopause reconnection, Geophys. Res. Lett., 19, 1731, 1992.

Lockwood, M., I. W. McCrea, G. H. Millward, R. J. Moffett, and H. Rishbeth, EISCAT observations of ion composition and temperature anisotropy in the high latitude F-region, J. Atmos. Terr. Phys., 55, 895, 1993.

Loranc, M., and J.-P. St-Maurice, A time-dependent gyro-kinetic model of thermal ion upflows in the high-latitude $\mathrm{F}$ region, $J$. Geophys. Res., 99, 17429, 1994.

Millward, G. H., R. J. Moffett, S. Quegan, and T. J. Fuller-Rowell, A coupled thermosphere-ionosphere-plasmasphere model, CTIP, STEP Handbook Ed. R. W. Schunk, 1996.

Moffett, R. J., B. Jenkins, and G. J. Bailey, A modelling study of anisotropic ion temperatures generated in the F-layer by subauroral ion drifts, Ann. Geophysicae, 11, 1051, 1993.

Pinnock, M., A. S. Rodger, J. R. Dudeney, K. B. Baker, P. T. Newell, R. A. Greenwald, and M. E. Greenspan, Observations of an enhanced convection channel in the cusp ionosphere, $J$. Geophys. Res., 98, 3767, 1993.

Quegan, S., G. J. Bailey, R. J. Moffett, R. A. Heelis, T. J. FullerRowell, D. Rees, and R. W. Spiro, A theoretical study of the distribution of ionization in the high-latitude ionosphere and the plasmasphere: first results on the mid-latitude trough and the light-ion trough, J. Atmos. Terr. Phys., 44, 619, 1982.

Rodger, A. S., M. Pinnock, J. R. Dudeney, J. Waterman, O. de la Beaujardiere, and K. B. Baker, Simultaneous two hemisphere observations of the presence of polar patches in the nightside ionosphere, Ann. Geophysicae, 12, 642, 1994a.

Rodger, A. S., M. Pinnock, J. R. Dudeney, K. B. Baker, and R. A. Greenwald, A new mechanism for polar patch formation, $J$. Geophys. Res., 99, 6425, 1994b.

Rosenberg, T. J., Z. Wang, A. S. Rodger, J. R. Dudeney, and K. B. Baker, Imaging riometer and HF radar density measurements of drifting $\mathrm{F}$ region electron density structures in the polar cap, J. Geophys. Res., 98, 7757, 1993.

Schunk, R. W., and J. J. Sojka, A three-dimensional timedependent model of the polar wind, J. Geophys. Res., 94, 8973, 1989. 
Schunk, R. W., W. J. Raitt, and P. M. Banks, Effects of electric fields on the daytime high-latitude $\mathrm{E}$ and $\mathrm{F}$ regions, J. Geophys. Res., 80, 3121, 1975.

Schunk, R. W., P. M. Banks, and W. J. Raitt, Effects of electric fields and other processes upon the nighttime high latitude $\mathrm{F}$ layer, J. Geophys. Res., 81, 3271, 1976.

Schunk, R. W., J. J. Sojka, and M. D. Bowline, Theoretical study of the electron temperature in the high-latitude ionosphere for solar maximum and winter conditions, J. Geophys. Res., 91, $12041,1986$.

Valladares, C. E., D. T. Decker, R. Sheehan, and D. N. Anderson, Modeling the formation of polar cap patches using large plasma flows, Radio Sci., 31, 573, 1996.
Weber, E. J., J. Buchau, J. G. Moore, J. R. Sharber, R. C. Livingstone, J. D. Winningham, and B. W. Reinisch, F layer ionization patches in the polar cap, J. Geophys. Res., 89, 1683, 1984.

Weber, E. J., J. A. Klobuchar, J. Buchau, H. C. Carlson, R. C. Livingstone, O. de la Beaujardiere, M. McCready, J. G. Moore, and G. J. Bishop, Polar cap F layer patches: structure and dynamics, J. Geophys. Res., 91, 12121, 1986.

Whitteker, J. H., The transient response of the topside ionosphere to precipitation, Planet. Space Sci., 25, 773, 1977.

Winkler, E., J.-P. St-Maurice, and A. R. Barakat, Results from improved Monte Carlo calculations of auroral ion velocity distributions, J. Geophys. Res., 97, 8399, 1992. 